Oldrich Hyks - Kristyna Neubergova - Pavel Pribyl*

\title{
INFLUENCE OF DRIVING FLUENCY ON ECONOMIC AND ECOLOGICAL ASPECTS OF TRANSPORT
}

The paper is focused on the influence of driving behaviour on fuel consumption and the subsequent environmental impacts. The main issue is to estimate the economic and environmental costs connected with the forced deceleration or stopping and the subsequent acceleration of a motor vehicle in urban traffic. Authors introduce a physical model of a vehicle with variable parameters that allows the calculation of economic and ecological losses in congestions on the basis of data generated by an arbitrary floating car. The losses include the lost kinetic energy of a vehicle during the forced braking, accelerated degradation of vehicle components, the loss of time of drivers and passengers and the increased ecological footprint. Energetic costs are estimated from the vehicle engine efficiency with which the fuel energy is transformed during an acceleration to kinetic energy of a vehicle lost during braking. Further, these costs are estimated from fuel calorific value and fuel price. Costs resulting from the degradation of vehicle components are estimated from their average stated lifetime.

Keywords: vehicle dynamics, fuel consumption, forced vehicle deceleration

\section{Introduction}

The aim of this paper is to provide an estimation of the economic and environmental costs due to the forced deceleration or stopping and the subsequent acceleration of a motor vehicle in urban traffic. This estimation is based on a dynamic vehicle model with variable parameters and thus it can be obtained from the data generated by an arbitrary floating car. The problem discussed in this treatise is particularly topical in rapidly developing urbanized areas around cities - see [1].

\section{Vehicle dynamics}

\subsection{Forces acting on a vehicle}

Consider a vehicle moving with an acceleration $\alpha$. In the travel direction, a driving force $F$ is acting. The movement is opposed by a vehicle resistance that includes: ${ }^{1}$ tire rolling resistance: $R_{f}=f m g$

\footnotetext{
${ }^{1}$ A movement in a horizontal plane is considered. For an uphill journey, a climbing resistance $R_{C}=m g \sin \alpha$ should be added, where a denotes an angle between a road and a horizontal direction. Similarly, all mentioned forces containing a term $m g$ would be multiplied by $\cos \alpha$. Nevertheless, we suppose that a driver getting over an elevation $h$, which requires an additional work $W=\int^{B} m g \sin \alpha \mathrm{ds}=m g h$, later returns to the initial altitude and earns the same energy back. In the case of the most frequent grades, the term $\cos \alpha$ would influence the price of one stopping and a subsequent acceleration at the third decimal position or further, the fuel consumption estimation would be affected at the fourth decimal position. Therefore, we put $\alpha=0$ and thus $\alpha=1$ in this paper.
}

aerodynamic drag: $R_{v}=\frac{1}{2} \rho c_{d} A v^{2}$

acceleration resistance of rotating parts: $R_{R}=m a \xi$

breaking force: $R_{B}=\mu m g x$

Here $f$ denotes a rolling resistance coefficient, $m$ vehicle mass, $g$ gravitational acceleration, $\rho$ air density, $c_{d}$ aerodynamic drag coefficient, $A$ projected front area, $v$ vehicle velocity, $a$ vehicle acceleration, $\xi$ coefficient including the inertia of rotating parts, $\mu$ tire adhesion coefficient, $x$ breaking intensity expressed by a value from the interval $[0,1]$.

As a model vehicle for calculations, Skoda Octavia 1.4 $\mathrm{MPI} / 55 \mathrm{~kW}$ with gasoline ignition engine has been chosen, since it belongs to the best-selling cars in the Czech Republic. Therefore, the following values are considered (see [2]): $f=0.015, m=1560 \mathrm{~kg}, c_{d}=0.30, A=2.069 \mathrm{~m}^{2}, \xi=0.04,{ }^{2}$ $g=9.81 \mathrm{~ms}^{-2}, \rho=1.25 \mathrm{kgm}^{-3}, \mu=0.8$ (for asphalt).

If the vehicle velocity $v$ is constant, the first Newton's motion law implies that the sum of acting forces is equal to zero:

$0=F-R_{v}-R_{f}=F-\frac{1}{2} \rho c_{d} A v^{2}-f m g$

The driving force $F$ can therefore be expressed in the form:

$F=\frac{1}{2} \rho c_{d} A v^{2}+f m g$

For the mentioned model vehicle, the driving force necessary to maintain a constant velocity of e.g. $v=50 \mathrm{kmh}^{-1} \doteq 13.89 \mathrm{~ms}^{-1}$ is

${ }^{2}$ We consider the least value from the interval between 0.04 and 0.7 , convenient for personal vehicles.

\footnotetext{
* ${ }^{1}$ Oldrich Hyks, ${ }^{2}$ Kristyna Neubergova, ${ }^{2}$ Pavel Pribyl

${ }^{1}$ Department of Applied Mathematics, Faculty of Transportation Sciences, Czech Technical University in Prague, Czech Republic

${ }^{2}$ Department of Transportation systems, Faculty of Transportation Sciences, Czech Technical University in Prague, Czech Republic E-mail: hyks@fd.cvut.cz
} 
approximately equal to $F=304.39 \mathrm{~N}$. The corresponding power (and thus also a consumption) is very small:

$P=F \cdot v=4227.64 \mathrm{~W}$

If the vehicle moves with an acceleration $\alpha$ (during the engine engagement, i.e., without braking), the second Newton's motion law implies:

$m a=F-R_{R}-R_{v}-R_{f}$

The driving force $F$ therefore satisfies the equation:

$$
F=m a+m a \xi+\frac{1}{2} \rho c_{d} A v^{2}+f m
$$

Denoting $\vartheta=1+\xi$, it can be expressed in the form:

$F=m a \vartheta+\frac{1}{2} \rho c_{d} A v^{2}+f m g$

To reach the maximal acceleration (from 0 to $100 \mathrm{~km}$ in $15.5 \mathrm{~s}$ ), the engine force acting on a vehicle has to be $F=3208.48 \mathrm{~N}$. For an instantaneous velocity of $50 \mathrm{kmh}^{-1}$ and the stated acceleration, the engine power would increase more than 10 times compared to the constant-velocity movement:

$$
P=F \cdot v=44562.27 \mathrm{~W}
$$

It is almost equal to the maximal engine power, the fuel consumption would also be almost maximal in this case. Nevertheless, the consumed energy is not yet lost. It is stored in the form of kinetic energy and consumed later during the vehicle deceleration or stopping. The ratio of a part utilized for a vehicle movement (when a car is put in neutral and moves by inertia) and a part dissipated to heat (during braking) is influenced by a driving style.

\subsection{Motion equations}

In the authors' paper [3], the investigation of the vehicle dynamics related to acceleration and braking was based on the corresponding first-order differential equations. In the former case, it is sufficient to express the acceleration $a$, which is a derivative of velocity, i.e., $a(t)=\dot{v}(t)$ Then one obtains the equation of motion as:

$$
\dot{v}(t)=\frac{1}{\vartheta}\left(\frac{F}{m}-\frac{1}{2 m} \rho c_{d} A v^{2}(t)-f g\right)
$$

Further, the braking of various intensities with a non-zero initial velocity and putting a car to neutral were investigated. In this case, the following equation holds:

$$
0=m a \vartheta+\frac{1}{2} \rho c_{d} A v^{2}+f m g+\mu m g x
$$

From this relation, an acceleration can be expressed (a negative value would indicate a deceleration). Putting $a(t)=\dot{v}(t)$ leads to the following equation of motion:

$$
\dot{v}(t)=\frac{1}{\vartheta}\left(-\frac{1}{2 m} \rho c_{d} A v(t)^{2}-f g-\mu g x\right)
$$

By solving Equation (12) and Equation (14), the time developments of acting forces, acceleration, velocity and travelled distance were obtained. Based on those results, an economic analysis of consumed fuel and lost time for various braking intensities was carried out. It was shown that the highest economic losses were connected to vehicle deceleration and stopping, and that they were caused not only by an increased consumption, but also by time losses and losses given by a vehicle fading. The obtained relations demonstrated a decisive influence of congestions on traffic economy.

\section{Energetic analysis}

\subsection{Consumption}

In the subsequent research, the mentioned relations were used for the analysis of data provided by a floating vehicle that was moving in a real traffic and recorded instantaneous velocity and travelled distance. An expression of an amount of energy utilized for vehicle movement for the given velocity behaviour was considered as follows.

The expended energy is equal to the work done by the driving force of an engine through tires acting on a road surface in a given segment of journey:

$W=\int_{s_{0}}^{s_{1}} F d s$

Due to Equation (10), a work element can be expressed in the following form:

$d W=F \cdot d s=\left(m a \vartheta+\frac{1}{2} \rho c_{d} A v^{2}+f m g\right) \cdot d s$

The amount of fuel consumed to earn this energy (for the sake of clarity, it is expressed directly in volume units) is given by the relation:

$d V_{W}=\frac{d W}{\eta H_{v}}$

where $\eta$ denotes an engine efficiency and $H_{V}$ stands for the caloric capacity of the used fuel, transformed to volume units. For the model vehicle considered in this paper, values $\eta=0.32$ and $H_{V}=$ $31.61 \mathrm{MJ} / 1$ were used. In reality, the total amount of the consumed fuel would be increased by a certain basal consumption that is necessary to keep an engine running and that is constant in time. For the considered model vehicle, this basal consumption is approximately equal to $V_{0}=1$ litre per hour. The total amount of the fuel consumed to carry out a work $d W$ in time $d t$ is therefore equal to the sum:

$d V=\frac{d W}{\eta H \nu}+V_{0} \cdot d t$ 


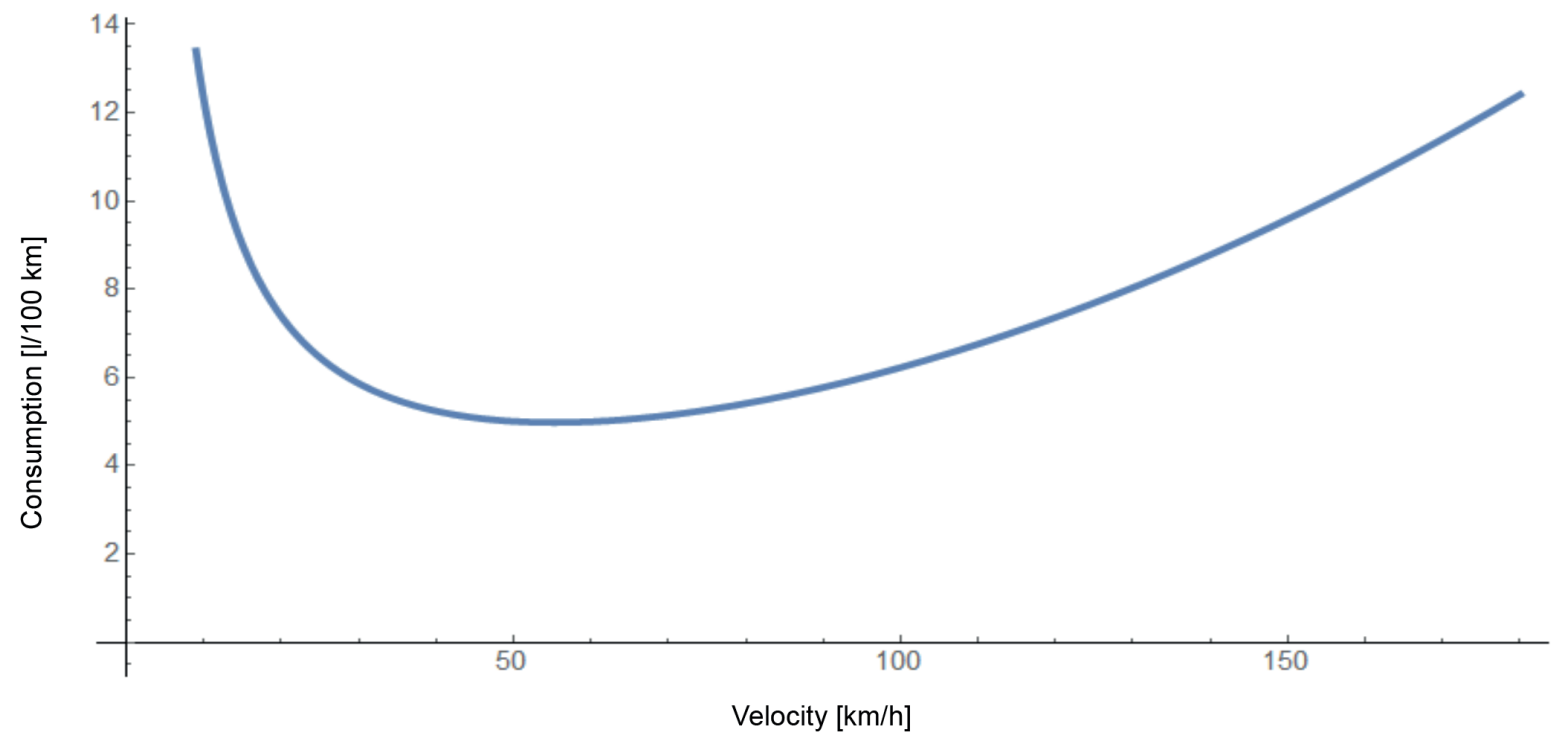

Figure 1 Dependence of the fuel consumption on velocity

For a known velocity $v=d s / d t$, the Equation (16) and Equation (18) imply:

$$
\begin{aligned}
d V & =\frac{F \cdot d s}{\eta H_{V}}+V_{0} \cdot \frac{d s}{v}= \\
& =\left[\frac{1}{\eta H_{V}} \cdot\left(m a \vartheta+\frac{1}{2} \rho c_{d} A v^{2}+f m g\right)+\frac{V_{0}}{v}\right] \cdot d s
\end{aligned}
$$

An instantaneous fuel consumption can thus be expressed as:

$$
\frac{d V}{d s}=\frac{1}{\eta H_{V}} \cdot\left(m a \vartheta+\frac{1}{2} \rho c_{d} A v^{2}+f m g\right)+\frac{V_{0}}{v}
$$

From Equation (20) it is obvious that the increase of fuel consumption in traffic congestions is caused not only by the kinetic energy losses. Another reason is that during the low velocities, the proportion of basal fuel consumption increases and so does the total fuel consumption, as well. The graph in Figure 1 demonstrates the dependence of the fuel consumption expressed in litres per $100 \mathrm{~km}$ on the velocity expressed in $\mathrm{km} / \mathrm{h}$ (for each velocity value, a stationary movement with $a=0$ is considered). Notice that the lowest consumption is reached for the velocity close to $50 \mathrm{~km} / \mathrm{h}$, i.e., close to the typical urban velocity.

\subsection{Fuel consumption for a model vehicle}

Using Equation (19), the values of the fuel consumption of the floating car driving on a part of the Prague circuit (Jizni spojka - South Connection) between the street 5. Kvetna and the Mrazovka tunnel, in various traffic densities, were estimated. Authors could work with a survey of instantaneous velocities $v$ and the corresponding distances $s_{i}$ (in 10 up to 30 metres). The volume of the consumed fuel was determined numerically as a sum of partial volumes consumed on individual segments.

For the segment $\left\langle s_{i}, s_{i+1}\right\rangle$, the motion was considered as uniformly accelerated with a constant acceleration
$a=\frac{\Delta v}{\Delta t}=\frac{v_{i+1}-v_{i}}{s_{i+1}-s_{i}} \cdot \frac{v_{i+1}+v_{i}}{2}=\frac{v_{i+1}^{2}-v_{i}^{2}}{2\left(s_{i+1}-s_{i}\right)}$

where the time $\Delta t$ was expressed as a function of an average velocity in the form $\Delta t=\Delta s / v_{a}$ with $v_{a}=\left(v_{i+1}+v_{i}\right) / 2$.

An absolute fuel consumption on a given segment was then obtained on the basis of the Equation (19):

$$
\begin{aligned}
\Delta V= & {\left[\frac { 1 } { \eta H _ { V } } \cdot \left(m \vartheta \cdot \frac{v_{i+1}^{2}}{2\left(s_{i+1}-s_{i}\right)}+\frac{1}{2} \rho c_{d} A .\right.\right.} \\
& \left.\left.\cdot\left(\frac{v_{i+1}+v_{i}}{2}\right)^{2}+f m g\right)+\frac{V_{0} \cdot 2}{v_{i+1}+v_{i}}\right] \cdot\left(s_{i+1}-s_{i}\right)
\end{aligned}
$$

If a vehicle deceleration is higher than the deceleration caused by natural resistances (i.e., in the case of braking), a computed driving force is negative, which means that the amount of fuel should be subtracted. Since the considered model car does not possess a recuperation system and a kinetic energy would be dissipated to heat, the driving force was set to be equal to zero.

At the end, the absolute fuel consumption during the travel on the segment of the length $7.61 \mathrm{~km}$ was replaced by a usually considered fuel consumption per $100 \mathrm{~km}$.

The two examples are presented in the following paragraphs. The first one is based on data recorded by a floating car in an afternoon peak hour, when the car was forced to break and even stop very often. It took $27.10 \mathrm{~min}$ to finish the whole journey, and the average velocity of the vehicle was $16.85 \mathrm{~km} / \mathrm{h}$. The graph illustrating the behaviour of instantaneous velocities is depicted in Figure 2. The value of an absolute fuel consumption, calculated on the basis of a model described in the present paper, is equal to 1.061 , which corresponds to the consumption of $13.911 / 100 \mathrm{~km}$.

The second example is based on the record from a morning peak when the vehicle movement was also nonstationary, but it was not necessary to slow down up to the zero velocity. This time, the same journey was finished in $7.98 \mathrm{~min}$ and the average velocity of the floating car was $57.19 \mathrm{~km} / \mathrm{h}$. The behaviour of instantaneous velocities is depicted in Figure 3. The calculated absolute fuel 


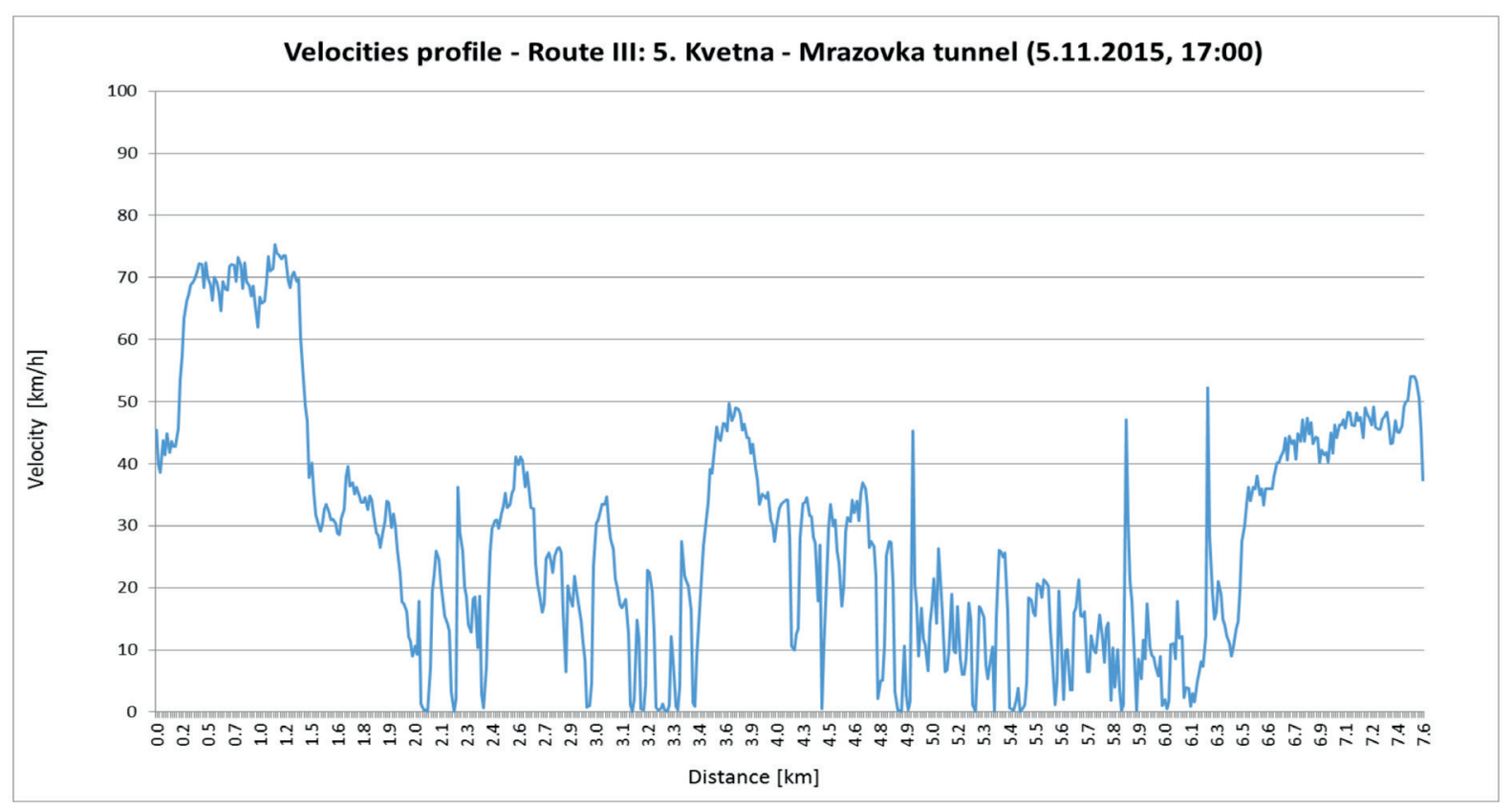

Figure 2 Behaviour of instantaneous velocities of a floating car in an afternoon peak

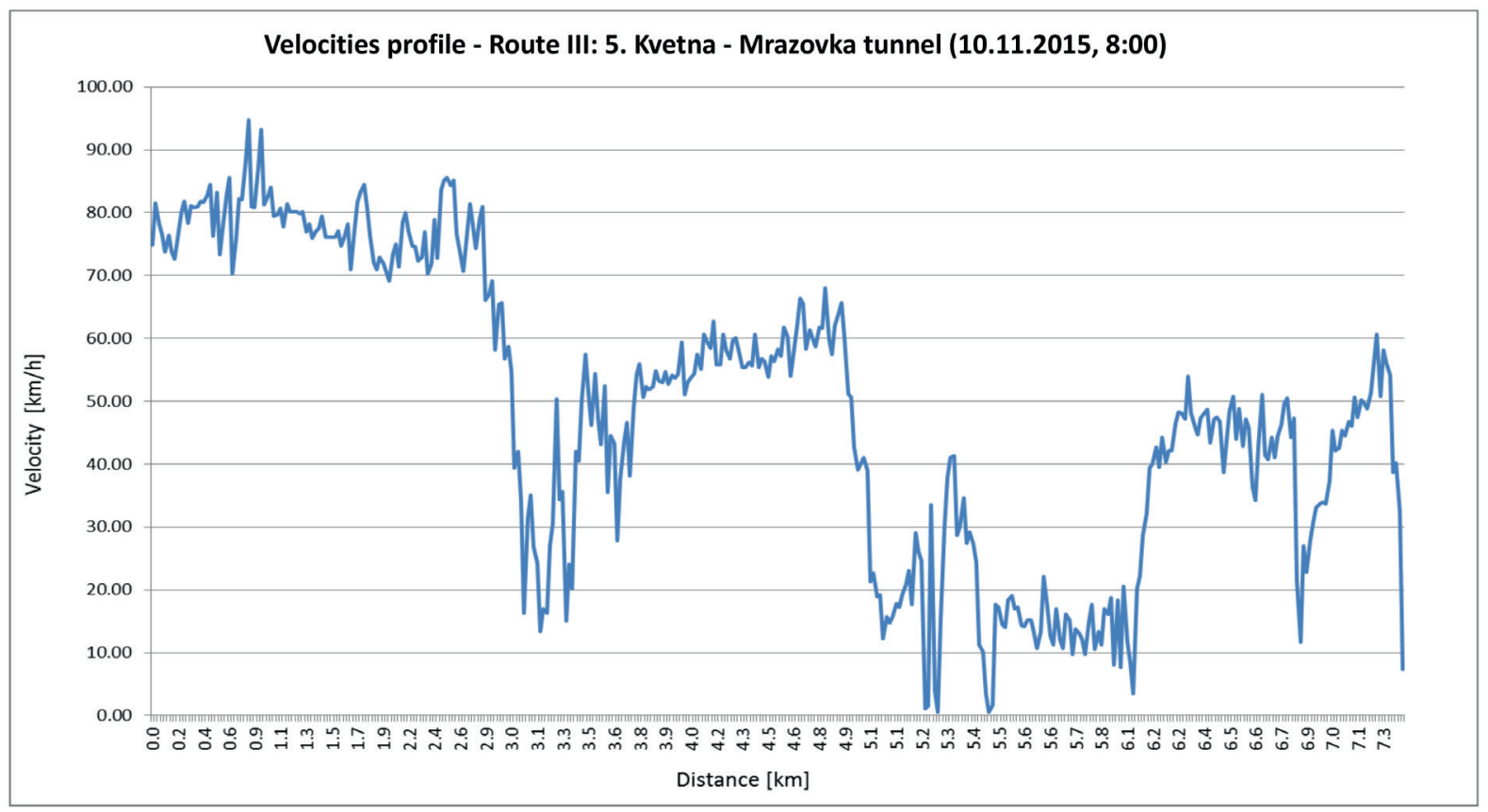

Figure 3 Behaviour of instantaneous velocities of a floating car in a morning peak

consumption is now equal to 0.641 , which corresponds to the consumption of $8.45 \mathrm{1} / 100 \mathrm{~km}$.

For a comparison, one can easily calculate the fuel consumption for a constant velocity of $80 \mathrm{~km} / \mathrm{h}$, namely for the maximal allowed velocity on the considered road. The absolute consumption would be equal to 0.411 , which corresponds to the consumption of $5.411 / 100 \mathrm{~km}$. The total time would be $5.71 \mathrm{~min}$ in this case.

The described model demonstrates that the fuel consumption indeed noticeably increases in congestions, which leads to a substantial increase of economic costs, too. On the short journey considered in the previous example, the absolute consumption increases approximately by 0.651 of gasoline in a peak hour compared to a stationary movement, which corresponds to the increase of economic costs by $15 \mathrm{CZK}$ (approximately 0.59 EUR).

\section{Emissions of carbon dioxide $\mathrm{CO}_{2}$}

During an ideal burning of fossil fuels, which are pure hydrocarbons, only $\mathrm{CO}_{2}$ a $\mathrm{H}_{2} \mathrm{O}$ would be emitted. Nevertheless, a great amount of other products are often formed in actual combustion processes, and only the following ones are being monitored: Carbon monoxide $\mathrm{CO}$, hydrocarbons $\mathrm{HCs}$, nitrogen oxides $\mathrm{NO}_{\mathrm{x}}$, sulphur dioxide $\mathrm{SO}_{2}$ and soot. Their ratio to the amount of $\mathrm{CO}_{2}$ and thus to the amount of consumed fuel is given 
by the quality of combustion and additional technologies, and it is defined by a Euro-norm I-V. Therefore, if one determines the amount of fuel consumed additionally due to stopping and subsequent acceleration, one can easily determine the corresponding amount of $\mathrm{CO}_{2}$ and according to the mentioned norm, the amounts of other selected combustion products, too. Moreover, $\mathrm{CO}_{2}$ is a greenhouse gas and its production represents an important parameter. Its production can only be decreased by decreasing the absolute fuel consumption.

For the estimation of actually emitted $\mathrm{CO}_{2}$, a methodology published by the United States Environmental Protection Agency (EPA) was used - see [4]. The calculation is based on chemical equations expressing amount of carbon in fuel during gasoline and diesel combustion. It also respects the recommendation of the Intergovernmental Panel on Climate Change (IPCC) to take into account the fact that only $99 \%$ of fuel volume is burned perfectly. The EPA methodology is based on the estimate that one gallon (3.7851) of gasoline contains $2.421 \mathrm{~kg}$ of carbon C, which corresponds to $0.644 \mathrm{~kg}$ of carbon in 1 liter of gasoline. The amount of emitted $\mathrm{CO}_{2}$ can be approximated relatively precisely by the multiplication of this value by the factor 0.99 expressing the degree of imperfection of fuel combustion, and further by the ratio of molar masses of carbon dioxide $\mathrm{CO}_{2}(44 \mathrm{~g} / \mathrm{mol})$ and carbon $\mathrm{C}(12 \mathrm{~g} / \mathrm{mol})$, which states how many times the mass of a molecule of carbon dioxide, created by bonding an aerial oxygen to an atom of carbon during the combustion, is greater than the mass of an atom of carbon alone:

$$
m=\left(0.644 \cdot 0.99 \cdot \frac{44}{12}\right) \mathrm{kg}=2.338 \mathrm{~kg}
$$

For the considered model vehicle and the journey (less than $8 \mathrm{~km}$ long) discussed in part 3.3, one obtains the conclusion that in an afternoon peak, this individual vehicle produces $1.55 \mathrm{~kg}$ of $\mathrm{CO}_{2}$ more than during the transit by a constant velocity of $80 \mathrm{~km} / \mathrm{h}$.

\section{Evaluation of the time costs}

There exist several possible approaches to evaluating the cost of time. Many of them are based on meta-analytic studies, e.g., the study by Wardman et al. [5]. For business trips, one of the most frequently used methods is the cost savings principle [6], when the time value is supposed to correspond to gross salary costs (i.e., gross salary plus an overhead), which are published in statistical overviews. In the Czech Republic, these costs are contained in the overviews of the Czech Statistical Office (CSU, see [7]). Travel compensations are also stated in the regulation published by the Ministry of Labour and Social Affairs (MPSV, see [8]). The case of private travels is certainly more difficult. Estimates based on willingness to pay is sometimes used, based either on manifested or on expressed preferences. In the Czech Republic, only several studies, aimed at this problem, have been performed (see e.g. [9], [10] and [11]), and a necessary representative investigation of travel behaviour of citizens has not yet been conducted. The values are therefore usually borrowed from foreign sources, e.g., from studies [5] and [6]. Nevertheless, those estimates are usually higher than the true domestic values. Based on the detailed search and analysis of existing methodologies, the value $300 \mathrm{CZK} / \mathrm{h}$ has been selected for the sake of this paper.

In the example considered in part 3.2, the travel time for the given journey was 21.39 minutes longer in an afternoon peak than in the case of a constant velocity of $80 \mathrm{~km} / \mathrm{h}$, which corresponds to a cost of $106.95 \mathrm{CZK}$ (4.20 EUR).

\section{Costs of vehicle component replacement}

To estimate the costs connected to the need to maintain vehicle components, only those components, the lifetime of which is rather a function of kilometres driven and driving style rather than the vehicle age as such, were considered. The cycle of their replacement is usually stated in terms of kilometres driven. As it was shown above, the fuel consumption is influenced by the driving style, the amount of stoppings and accelerations and braking intensity. Therefore, if one transforms the component price to a price per kilometre driven and consequently to the price per one litre of consumed fuel, one can evaluate the forced stoppings in traffic congestions not only with respect to the price of an additional amount of fuel, but with respect to increased component replacement costs, as well:

$$
\begin{aligned}
C_{f}= & \sum_{i=1}^{n} \frac{\text { component price }[\mathrm{CZK}]}{\text { lifetime }[\mathrm{km}]} \\
& \frac{100[\mathrm{~km}]}{\text { fuel consumption }[\mathrm{l}]}
\end{aligned}
$$

To get a rough estimate, one can consider only the components that have to be replaced most frequently, their replacement rates depend substantially on a driving style and their prices are significant, namely gears (ca. 18000 CZK (708 EUR) per $120000 \mathrm{~km}$, brakes (ca. 18000 CZK (708 EUR) per $120000 \mathrm{~km}$ ) and tires (ca. $4000 \mathrm{CZK}$ (157 EUR) per $40000 \mathrm{~km}$ ). For the model vehicle, one obtains the following estimation of costs given by component replacement per litre of a fuel:

$$
\begin{aligned}
C_{f} & =\left(\frac{18000}{120000}+\frac{18000}{120000}+\frac{4000}{40000}\right) \cdot \frac{100}{6.9} \doteq \\
& \doteq 5.80 \frac{\mathrm{CZK}}{1}\left(0.23 \frac{\mathrm{EUR}}{1}\right)
\end{aligned}
$$

In the example discussed in part 3.2, the fuel consumption in an afternoon peak was 0.651 of gasoline higher that in the case of a constant velocity of $80 \mathrm{~km} / \mathrm{h}$. It corresponds to the loss caused by additional component replacement in congestions in the range of 3.77 CZK (0.15 EUR).

\section{Conclusion}

A question may be raised, what is the value of calculating fuel consumption based on the physical model and data (velocity and distance) recorded by a floating vehicle, when consumption can be measured directly by the testing car. There exist several reasons for that. First of all, the measurement of an actual consumption is technically difficult. Data from a dashboard computer are only approximate, the consumption is estimated on the basis of the engine revolutions and openings of a fuel flap. The more exact 
measurement of the actual amount of consumed fuel would require the replacement of a standard fuel tank by a special one enabling reading fuel decrease. This solution is unusual and demanding with respect to realization, as well as operation and maintenance.

The main reason is the fact that a direct consumption measure would only allow to measure the fuel consumption for a unique type of a vehicle used as a floating one. The described physical model allows the modification of the input parameters completely arbitrarily, and thus allows e.g. the estimation of a consumption of a truck based on data from a floating personal vehicle, even in segments where trucks are not allowed to drive.

The model can also become a part of a virtual transit simulation on some journey after its planned modification or even on a journey that does not exist at all.

In the forthcoming research, we would like to acquire data from an accelerometer of a floating car to find the behaviour of acceleration as a function of time, with the location control based on the GPS, and to use those data for the further improvement of the model.

\section{References}

[1] NEUBERGOVA K.: Urban Sprawl Syndrome and Transport. Proceedings of IV. Czech-Slovak Scientific Conference "Transport, Health and Environment”, Czech Republic, 203-208, 2010.

[2] Technical Specification of Skoda Octavia Cars [online] (in Czech). Available: http://www.auto.cz/kompletni-technicka-data-noveoctavie-17169.

[3] HYKS O., NEUBERGOVA K.: Influence of Congestions on Economy and Ecological Footprint of Individual Vehicle Transportation (in Czech). Proceedings of X. Czech-Slovak Scientific Conference "Transport, Health and Environment”, Czech Republic, 137-145, 2016.

[4] EPA - ENVIRONMENTAL PROTECTION AGENCY: Greenhouse Gas Emissions from a Typical Passenger Vehicle. EPA, Ann Arbor, 2014.

[5] WARDMAN M., CHINTAKAYALA P., DE JONG G., FERRER D.: European Wide Meta-Analysis of Values of Travel Time, Final Report to the European Investment Bank. University of Leeds, Leeds, 2012.

[6] HEATCO: Developing Harmonised European Approaches for Transport Costing and Project Assessment [online]. IER, 2004. Available: http://heatco.ier.uni-stuttgart.de/.

[7] CZECH STATISTICAL OFFICE: Consumer Price Indexes. Average Fuel Prices by Month from 2015 to 2017 [online] (in Czech) Available: https://www.czso.cz/csu/czso/indexy-spotrebitelskych-cen-zivotnich-nakladu-zakladni-cleneni-prosinec-2017.

[8] MINISTRY OF LABOUR AND SOCIAL AFFAIRS: Regulation of the Ministry of Labour and Social Affairs Nr. 385/2015 Sb. [online] (in Czech). Prague, 2016. Available: http://www.mpsv.cz/files/clanky/23440/vyhlaska_X2016.pdf.

[9] BRUHA J, BRUHOVA - FOLTYNOVA H.: Estimation of the Value of Time in the Czech Republic [online]. KIT, Kolin. Available: https://www.czp.cuni.cz/czp/images/stories/ Vystupy/TranExt/4-Bruha-Econometric_Estimation_of_Value_of\%20Time-Pilsen_ study.pdf, 2011.

[10] MACA V., MELICHAR J., et al: Methodology of Traffic Externalities Quantification (in Czech). UK and ATEM, Prague, 2013.

[11] MACA V., et al: TranExt, Quantification of External Traffic Costs in the Czech Republic [online] (in Czech). Available: https:// www.czp.cuni.cz/czp/index.php/cz/ukoncene/18-tranext-vav-md-20072011. 